\title{
Impact of molar teeth distalization with clear aligners on occlusal vertical dimension: a retrospective study
}

\author{
Silvia Caruso ${ }^{1+}$, Alessandro Nota ${ }^{1,2^{*}+}$, Shideh Ehsani ${ }^{2}$, Elena Maddalone ${ }^{2}$, Kenji Ojima ${ }^{3}$ and Simona Tecco $^{2}$ (D)
}

\begin{abstract}
Background: A common strategy in the non-extraction treatment of Class II molar relationship is maxillary molar distalization, which could increase lower face height and cause clockwise mandibular rotation. The aim of this retrospective study was to analyse the effects on vertical dentoskeletal dimension of young adults treated with sequential distalization with orthodontic aligners.
\end{abstract}

Methods: Lateral cephalometric radiographs of 10 subjects (8 females 2 males; mean age $22.7 \pm 5.3$ years) treated with upper molars sequential distalization with orthodontic aligners (Invisalign, Align Technology, San Josè, California, USA) were analyzed.

Results: No statistically significant difference was observed for the primary outcome SN-GoGn between T0 and T1 and it was recorded a mean variation of $0.1 \pm 2.0$ degrees. Statistically significant differences were found in the linear position of the upper molars (6-PP, 7-PP) the molar class relationship parameter (MR) and the upper incisive inclination (1^PP) with at least $p<0.01$.

Conclusions: Upper molar distalization with orthodontic aligners guarantee an excellent control of the vertical dimension representing an ideal solution for the treatment of hyperdivergent or openbite subjects. It also allows an excellent control of the incisal torque without loss of anchorage during the orthodontic procedure.

Keywords: Malocclusion, angle class II, Vertical dimension, Tooth movement techniques, Orthodontic appliances, removable

\section{Background}

One of the most common strategies applied in the nonextraction treatment of Class II molar relationship is maxillary molar distalization. The major indication are patients with maxillary dentoalveolar protrusion or minor skeletal discrepancies [1,2].

Since 1950's headgear has been the most frequently used appliance for maxillary molar distalization. Unfortunately this appliance requires considerable patient compliance $[3,4]$ so several alternative intraoral methods had been proposed to reduce or cut out patient's cooperation $[5,6]$. Despite the effectiveness of many of

\footnotetext{
*Correspondence: dr.alessandro.nota@gmail.com

'Department of Life, Health and Environmental Sciences, University of L'Aquila, Piazzale Salvatore Tommasi 1, 67100 L'Aquila, Coppito, Italy ${ }^{2}$ Dental School, Vita-Salute University and IRCCS San Raffaele Hospital, Via Olgettina, 58, 20132 Milan, Italy

Full list of author information is available at the end of the article
}

these appliances clinicians must consider many sideeffects: increase in lower face height, clockwise mandibular rotation, extrusion of first premolars, undesirable tipping of the maxillary molars and loss of anterior anchorage during distalization [1, 7-10]. Most of these side effects involve an increase of the vertical dimension of the treated subjects, keeping this treatment procedure generally contraindicated in hyperdivergents $[2,11]$.

In the last decades, the orthodontic treatment with removable clear aligners has become an increasingly common choice because of the growing number of adult patients that ask for aesthetic and comfortable alternatives to conventional fixed appliances [12, 13]. Clear aligners are based on computer aided design procedures. The orthodontic treatment with the Invisalign (Align Technology, San Josè, California, USA) system

(C) The Author(s). 2019 Open Access This article is distributed under the terms of the Creative Commons Attribution 4.0 International License (http://creativecommons.org/licenses/by/4.0/), which permits unrestricted use, distribution, and 
is a digitized process that starts from the acquisition of a 3D model of the dental arches allowing the planning of teeth movements with a proper software. The aligner allows the control of 3D movements by holding teeth on all the surfaces (vestibular, palatallingual and occlusal) and applying proper forces thanks to attachments of different size and shape and other specific features.

Aligners can also provide a class II correction by a sequential maxillary molar distalization $[14,15]$ with a high predictability $(88 \%)$ of the distalization movement of upper molars if supported by the presence of attachments on the tooth surface assessed by Simon et al. [16, 17]. Ravera et al. [15] showed that clear aligners are suitable for distalizing maxillary up to $2-3 \mathrm{~mm}$ without significant mesiodistal tipping movement, and it seems that this result could be improved if combined with photobiomodulation or other acceleration tooth movement systems [18-20].

The aim of this retrospective study was to analyze the effects of class II treatment by sequential distalization with orthodontic aligners on vertical dentoskeletal dimension.

\section{Methods}

\section{Subjects and procedure}

This retrospective study analysed lateral cephalometric radiographs of a sample of 10 subjects (8 females 2 males; mean age $22.7 \pm 5.3$ years) treated with sequential distalization with orthodontic aligners (Invisalign, Align Technology, San Josè, California, USA). Figure 1 shows the lateral cephalometric radiographs of a patient included in this study. The retrospective study was ethically approved by the Institution, the procedures were in accordance with the declaration of Helsinki and all the subjects signed a consent form. Bilateral molar class II or end-to-end molar relationship, absence of mesial rotation of the upper first molars, mild or light crowding in the upper arch, absence of periodontal disease, absence of previous prosthodontic treatments of the upper molars, good compliance during the treatment, good quality and definition of the radiographs were the study inclusion criteria. All the subjects that satisfied the inclusion criteria were included in the study and were successfully treated even if the treatment success wasn't an inclusion criterion. The mean treatment time was of $1.9 \pm 0.5$ years. Four subjects were excluded from the initial study sample of 14 subjects because they didn't match with the inclusion criteria.

Lateral cephalograms in habitual occlusion were considered for the study. Cephalometric head films were collected at the beginning (T0) at the end of treatment (T1) with orthodontic aligners.

The treatment of sequential upper arch distalization (Fig. 2) was performed by the same expert operator (K.O.) as proposed by Align Technology and described by Ravera et al. [15] using II class elastics and rectangular vertical attachments on the upper molars and premolars.

Radiographs were manually traced by the same expert operator (S.E.) blinded about the study. A total of fourteen cephalometric parameters (5 linear, 9 angular) were measured and recorded for each cephalogram, afterwards the relationship between the posterior facial height and the anterior facial height were calculated.

SN-GoGn $\left(^{\circ}\right)$ was considered as primary outcome. [21] It shows the impact of the orthodontic procedure on the sagittal vertical dimension of the samples.

\section{Intra-observer method error}

In order to verify the method error, ten lateral cephalometric radiographs underwent to the same cephalometric analysis two times by the same operator, at a distance of about 2 weeks. Applying the Dahlberg's formula, the method error resulted lower than the standard deviation observed in the whole sample for the variable. For the primary outcome the measured method error was $0.98^{\circ}$.

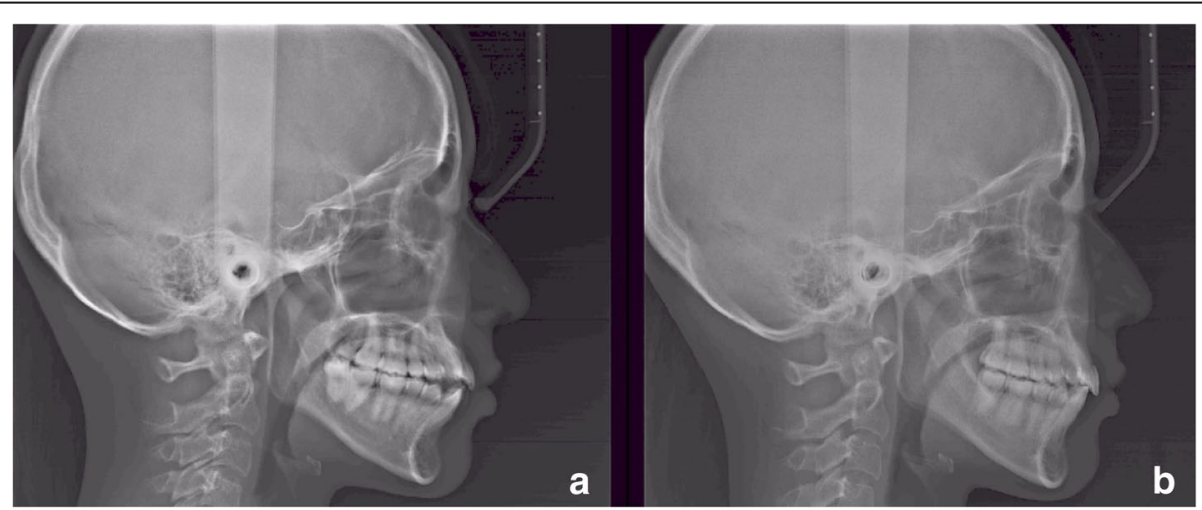

Fig. 1 a-b: Lateral cephalometric radiographs of a patient, before the orthodontic treatment with sequential distalization (a) and after treatment (b) 


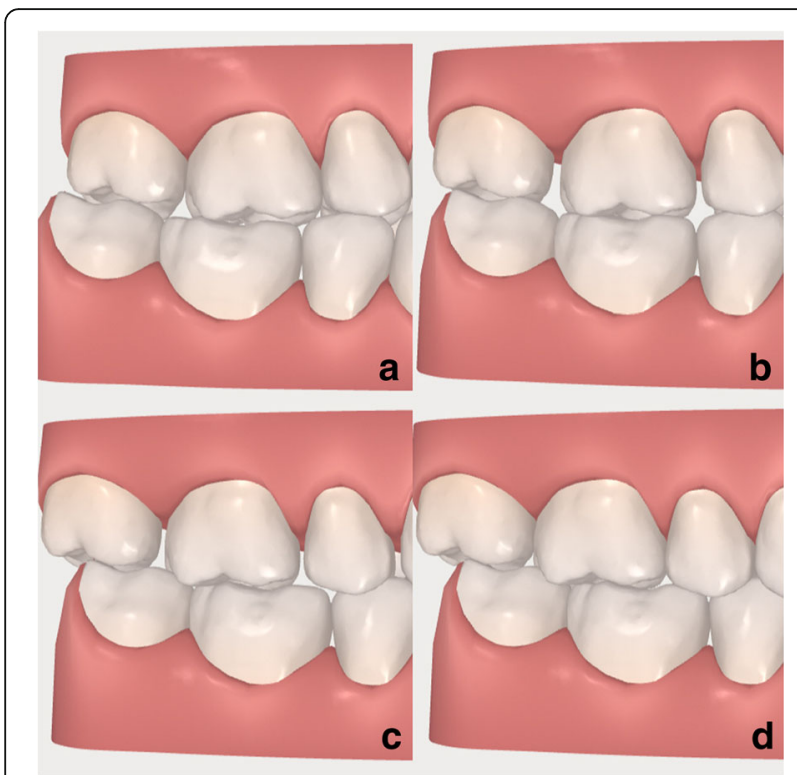

Fig. 2 a-d: Sequence of tooth movement with distalization of the upper teeth, from a to $\mathbf{d}$. Frames extracted by a ClinCheck ${ }^{\circledR}$ (Align Technology, San Josè, California, USA)

The intraclass correlation coefficient (ICC) was also calculated, for the primary outcome, obtaining a value of 0.99 .

\section{Statistical analysis}

Descriptive statistics were calculated for each variable of recorded data.

The normality assumption of the data was confirmed by the Shapiro-Wilk test. Thus, the differences between before (T0) and after treatment (T1) were compared with the paired-t test. The level of significance was set at $P<0.05$.

\section{Results}

Descriptive data, means and standard deviation (SD), of the recorded parameters are reported in Table 1. Figure 3 shows a lateral intra-oral view of one of the treated patients, before and after treatment.

No statistically significant difference was observed for the primary outcome SN-GoGn between $\mathrm{T} 0$ and $\mathrm{T} 1$ and it was recorded a mean variation of $0.1 \pm 2.0$ degrees. Similarly no statistically significant difference was observed for the linear measurements of vertical dimension (S-Go;N-Me).

Statistically significant differences were found for the linear position of the upper molars (6-PP, 7-PP) the MR parameter and the upper incisor inclination $\left(1^{\wedge} \mathrm{PP}\right)$ with at least $p<0.01$.

No significant variations were observed for the other cephalometric parameters analysed.
Table 1 Descriptive data and statistical analysis of the differences between $\mathrm{T} 0$ and $\mathrm{T} 1$

\begin{tabular}{|c|c|c|c|c|c|}
\hline \multirow{2}{*}{ 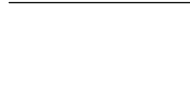 } & \multicolumn{2}{|l|}{ T0 } & \multicolumn{2}{|l|}{$\mathrm{T} 1$} & \multirow{2}{*}{$\begin{array}{l}\text { Student T Te } \\
\text { Sig. }\end{array}$} \\
\hline & MEAN & $\mathrm{SD}$ & MEAN & SD & \\
\hline SNA $\left(^{\circ}\right)$ & 82.4 & 4.7 & 83.0 & 4.9 & 0.559 \\
\hline SNB $\left(^{\circ}\right)$ & 79.0 & 4.9 & 78.7 & 4.9 & 0.403 \\
\hline ANB $\left(^{\circ}\right)$ & 3.4 & 3.3 & 4.3 & 3.2 & 0.195 \\
\hline$S N \wedge G o G n\left({ }^{\circ}\right)$ & 35.6 & 6.9 & 35.4 & 8.4 & 0.445 \\
\hline $\mathrm{SN} \wedge \mathrm{fOP}\left({ }^{\circ}\right)$ & 18.9 & 4.1 & 20.6 & 6.3 & 0.122 \\
\hline $\mathrm{SN} \wedge \mathrm{PP}\left({ }^{\circ}\right)$ & 7.3 & 6.1 & 6.3 & 5.7 & 0.309 \\
\hline 6-PP (mm) & 25.0 & 3.0 & 23.0 & 3.0 & $0.000^{* * * *}$ \\
\hline $6 \wedge P P\left({ }^{\circ}\right)$ & 81.2 & 3.5 & 79.9 & 4.4 & 0.220 \\
\hline 7-PP (mm) & 16.0 & 3.0 & 13.0 & 3.0 & $0.000^{* * * *}$ \\
\hline $7 \wedge P P\left({ }^{\circ}\right)$ & 81.7 & 5.6 & 82.3 & 4.3 & 0.352 \\
\hline $1 \wedge P P\left({ }^{\circ}\right)$ & 118.3 & 6.6 & 104.8 & 10.9 & $0.006^{* * *}$ \\
\hline $\mathrm{MR}(\mathrm{mm})$ & 3.1 & 1.4 & 1.2 & 0.6 & $0.000^{* * * *}$ \\
\hline S-Go (mm) & 68.0 & 6.1 & 68.0 & 6.8 & 0.476 \\
\hline $\mathrm{N}-\mathrm{Me}(\mathrm{mm})$ & 109.0 & 6.0 & 108.9 & 6.2 & 0.438 \\
\hline S-Go/N-Me & 0.62 & 0.05 & 0.63 & 0.06 & 0.421 \\
\hline
\end{tabular}

\section{Discussion}

In literature it was observed that different orthodontic appliances caused undesired effects on the upper molars distalization procedure and on the sagittal vertical pattern as clockwise rotation of the mandibular plane and increase in the anterior facial height [22-26]. This finding implied a contraindication of the upper molar distalization in hyperdivergent subjects.

The present retrospective study analysed the sagittal vertical dimension changes associated with successful orthodontic treatment of subjects with second molar class by sequential upper molar distalization performed with clear aligners. A previous study showed a high predictability of clear aligners in performing the upper molars distalization movement with absence of distal tipping [15].

Results indicated that there were no changes in the subject divergence by observing variations of the $\mathrm{SN}$ GoGn angle lower than $1^{\circ}$. The present findings suggest that clear aligners allow a good control of mandibular divergence during molar distalization. These results are in accordance with what reported by Ravera et al. [15] as a secondary outcome of their study.

Similarly, it was observed a significant distal movement of the upper molars (and the related correction in molar relationship) with absence of distal tipping, confirming the capability of performing a distal body movement of the upper molars by clear aligners with a control of the vertical dimensions the opposite of what reported by previous authors [22-26] with other orthodontic appliances. 

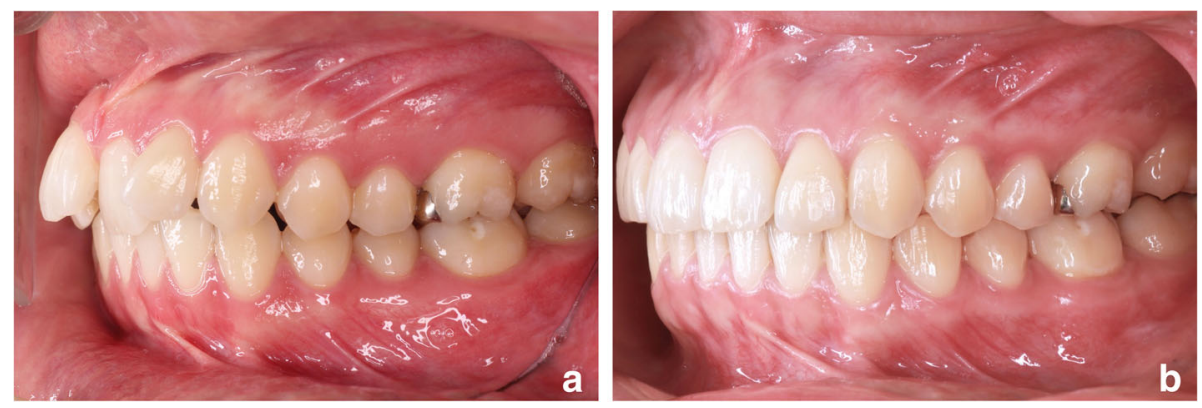

Fig. $\mathbf{3}$ a-b: Lateral intra-oral view of a patient, before the orthodontic treatment (a) and after treatment (b)

No significant rotations of the maxillary and functional occlusal plane were observed. No significant changes were observed in the sagittal position of mandible and maxilla, in contrast to what reported by Ravera et al. [15] that showed a significant reduction of the ANB angle.

Previous studies showed a control of the vertical dimension during distalization with pendulum appliance properly activated by expert operators [2, 22, 24]. Recent review indicates a molar distal tipping that range between $8.4^{\circ}$ and $14.5^{\circ}$, much higher than what reported by the present study (mean tipping of $1.3^{\circ}$ ), furthermore a trend to an anterior anchorage loss was observed with pendulum appliance if bone anchorage was not applied [25, 26].

No anchorage loss was observed on upper incisors that had a significant mean reduction of their inclination of $13.2^{\circ}$ showing a torque control much higher than what reported by Ravera et al. [15].

Looking at the results of this study, the upper molar distalization performed with clear aligners seems to overcome various side effects related with this orthodontic procedure typically observed with other appliances in previous studies $[1,7-10]$ and seems to allow a predictable distal body movement of upper molars [15-17] with a control of the vertical dimension and of the incisal torque. This could be related with the aligner design, that allows the control of 3D movements by holding teeth on all the surfaces (vestibular, palatal-lingual and occlusal) and applying proper forces thanks to properly digitally planned attachments.

Consequently, orthodontic aligners could represent an effective alternative for upper molar distalization especially in hyperdivergent or openbite subjects at least for distal molar movements up to $2-3 \mathrm{~mm}$. Further studies should be conducted on distal molar movements higher than $2-3 \mathrm{~mm}$ and on hyperdivergent subjects.

At the authors' knowledge this is the first study that analysed as a primary outcome the effects of the upper molar distalization orthodontic technique with clear aligners on the vertical dimension of subjects with molar class II malocclusion.

\section{Limitations of the study}

Limitations of this study are the low sample size and the limited mean amount of distal movement that should be increased in future studies to confirm the control of the vertical dimension. Furthermore, the retrospective design should be replaced by a longitudinal design in order to reduce the risk of bias.

\section{Conclusions}

Upper molar distalization with orthodontic aligners properly digitally planned by the orthodontist seems to allow a good control of the vertical dimension. A satisfactory control of the incisal torque without loss of anchorage during the orthodontic procedure was also observed.

Further studies should be performed to confirm the results of the present study and analyse if the upper distalization with orthodontic aligners could represent an effective alternative for the treatment of class II subjects even with hyperdivergent or openbite skeletal patterns.

\section{Abbreviation}

MR: Molar Relationship

\section{Acknowledgements}

The authors acknowledge dr. Atanaz Darvizeh for her contribution to English language revision.

\section{Authors' contributions}

SC concept, data collection, manuscript revision, accountability for research integrity and accuracy, approval of the article. AN concept, design, writing of the article, methodology, data analysis, data interpretation, critical revisions, approval of the article. SE data collection, data analysis, manuscript writing, approval of the article. EM manuscript writing, data collection, critical revisions, approval of the article. KO data collection, clinical procedures, critical revisions, approval of the article. ST concept, design, writing of the article, methodology, data analysis, data interpretation, critical revisions, approval of the article. All authors read and approved the final manuscript. 


\section{Funding}

This research did not receive any specific grant from funding agencies in the public, commercial, or not-for-profit sectors.

\section{Availability of data and materials}

The data that support the findings of this study are available from the archive of the University of L'Aquila, but restrictions apply to the availability of these data, which were used under permission and consent for the current study, and so are not publicly available. Data are however available from the authors upon reasonable request and with permission of the patients and the Ethic Committee of the University of L'Aquila.

\section{Ethics approval and consent to participate}

The study was ethically approved by the Ethic Committee of the University of L'Aquila, Italy (Document DR206/2013). The treated subjects gave the consent to the analysis of their documentation for research purposes. The retrospective study was ethically approved by the Institution, the procedures were in accordance with the declaration of Helsinki and all the subjects signed a consent form.

\section{Consent for publication}

Not applicable.

\section{Competing interests}

The authors declare that they have no competing interests.

\section{Author details}

${ }^{1}$ Department of Life, Health and Environmental Sciences, University of L'Aquila, Piazzale Salvatore Tommasi 1, 67100 L'Aquila, Coppito, Italy. ${ }^{2}$ Dental School, Vita-Salute University and IRCCS San Raffaele Hospital, Via Olgettina, 58, 20132 Milan, Italy. ${ }^{3}$ Private Practice of Orthodontics, Tokyo, Japan.

Received: 6 April 2019 Accepted: 7 August 2019

Published online: 13 August 2019

\section{References}

1. Bolla E, Muratore F, Carano A, Bowman SJ. Evaluation of maxillary molar distalization with the distal jet: a comparison with other contemporary methods. Angle Orthod. 2002;72:481-94.

2. Lione R, Franchi L, Laganà G, Cozza P. Effects of cervical headgear and pendulum appliance on vertical dimension in growing subjects: a retrospective controlled clinical trial. Eur J Orthod. 2015;37:338-44.

3. Baldini A, Nota A, Santariello C, Assi V, Ballanti F, Cozza P. Influence of activation protocol on perceived pain during rapid maxillary expansion. Angle Orthod. 2015;85:1015-20

4. Clemmer EJ, Hayes EW. Patient cooperation in wearing orthodontic headgear. Am J Orthod. 1979;75:517-24.

5. Fuziy A, Rodrigues de Almeida R, Janson G, Angelieri F, Pinzan A. Sagittal, vertical, and transverse changes consequent to maxillary molar distalization with the pendulum appliance. Am J Orthod Dentofac Orthop. 2006;130:502-10.

6. Fontana M, Cozzani M, Caprioglio A. Non-compliance maxillary molar distalizing appliances: an overview of the last decade. Prog Orthod. 2012;13:173-84

7. Byloff FK, Darendeliler MA, Clar E, Darendeliler A. Distal molar movement using the pendulum appliance. Part 2: the effects of maxillary molar root uprighting bends. Angle Orthod. 1997;67:261-70

8. Bussick TJ, McNamara JA. Dentoalveolar and skeletal changes associated with the pendulum appliance. Am J Orthod Dentofac Orthop. 2000:117:333-43.

9. Lima Filho RMA, Lima AL, de Oliveira Ruellas AC. Longitudinal study of anteroposterior and vertical maxillary changes in skeletal class II patients treated with Kloehn cervical headgear. Angle Orthod. 2003;73:187-93.

10. Mariani L, Maino G, Caprioglio A. Skeletal versus conventional intraoral anchorage for the treatment of class II malocclusion: dentoalveolar and skeletal effects. Prog Orthod. 2014;15:43.

11. Saccucci M, Polimeni A, Festa F, Tecco S. Do skeletal cephalometric characteristics correlate with condylar volume, surface and shape? A 3D analysis. Head Face Med. 2012;8:15.

12. Giancotti A, Mampieri G, Greco M. Correction of deep bite in adults using the Invisalign system. J Clin Orthod. 2008:42:719-26 quiz 728.

13. Miller DB. Invisalign in TMD treatment. Int J Orthod Milwaukee. 2009;20:15-9.
14. Fischer K. Invisalign treatment of dental class II malocclusions without auxiliaries. J Clin Orthod. 2010:44:665-72 quiz 687.

15. Ravera S, Castroflorio T, Garino F, Daher S, Cugliari G, Deregibus A. Maxillary molar distalization with aligners in adult patients: a multicenter retrospective study. Prog Orthod. 2016;17:12.

16. Simon M, Keilig L, Schwarze J, Jung BA, Bourauel C. Forces and moments generated by removable thermoplastic aligners: incisor torque, premolar derotation, and molar distalization. Am J Orthod Dentofac Orthop. 2014;145:728-36.

17. Rossini G, Parrini S, Castroflorio T, Deregibus A, Debernardi CL. Efficacy of clear aligners in controlling orthodontic tooth movement: a systematic review. Angle Orthod. 2015;85:881-9.

18. Ojima K, Dan C, Watanabe H, Kumagai Y. Upper molar distalization with Invisalign treatment accelerated by photobiomodulation. J Clin Orthod. 2018:52:675-83.

19. Cassetta M, Altieri F, Barbato E. The combined use of corticotomy and clear aligners: a case report. Angle Orthod. 2016:86:862-70.

20. Long H, Pyakurel U, Wang Y, Liao L, Zhou Y, Lai W. Interventions for accelerating orthodontic tooth movement: a systematic review. Angle Orthod. 2013:83:164-71

21. Ahmed M, Shaikh A, Fida M. Diagnostic performance of various cephalometric parameters for the assessment of vertical growth pattern. Dental Press J Orthod. 2016;21:41-9.

22. Angelieri F, de Almeida RR, Janson G, Castanha Henriques JF, Pinzan A Comparison of the effects produced by headgear and pendulum appliances followed by fixed orthodontic treatment. Eur J Orthod. 2008;30:572-9.

23. Kirjavainen M, Kirjavainen T, Hurmerinta K, Haavikko K. Orthopedic cervical headgear with an expanded inner bow in class II correction. Angle Orthod. 2000;70:317-25

24. Mossaz CF, Byloff FK, Kiliaridis S. Cervical headgear vs pendulum appliance for the treatment of moderate skeletal class II malocclusion. Am J Orthod Dentofac Orthop. 2007;132:616-23.

25. Caprioglio A, Fontana M, Longoni E, Cozzani M. Long-term evaluation of the molar movements following pendulum and fixed appliances. Angle Orthod. 2013:83:447-54

26. Al-Thomali Y, Basha S, Mohamed RN. Pendulum and modified pendulum appliances for maxillary molar distalization in class II malocclusion - a systematic review. Acta Odontol Scand. 2017;75:394-401.

\section{Publisher's Note}

Springer Nature remains neutral with regard to jurisdictional claims in published maps and institutional affiliations.

Ready to submit your research? Choose BMC and benefit from:

- fast, convenient online submission

- thorough peer review by experienced researchers in your field

- rapid publication on acceptance

- support for research data, including large and complex data types

- gold Open Access which fosters wider collaboration and increased citations

- maximum visibility for your research: over $100 \mathrm{M}$ website views per year

At BMC, research is always in progress.

Learn more biomedcentral.com/submissions 